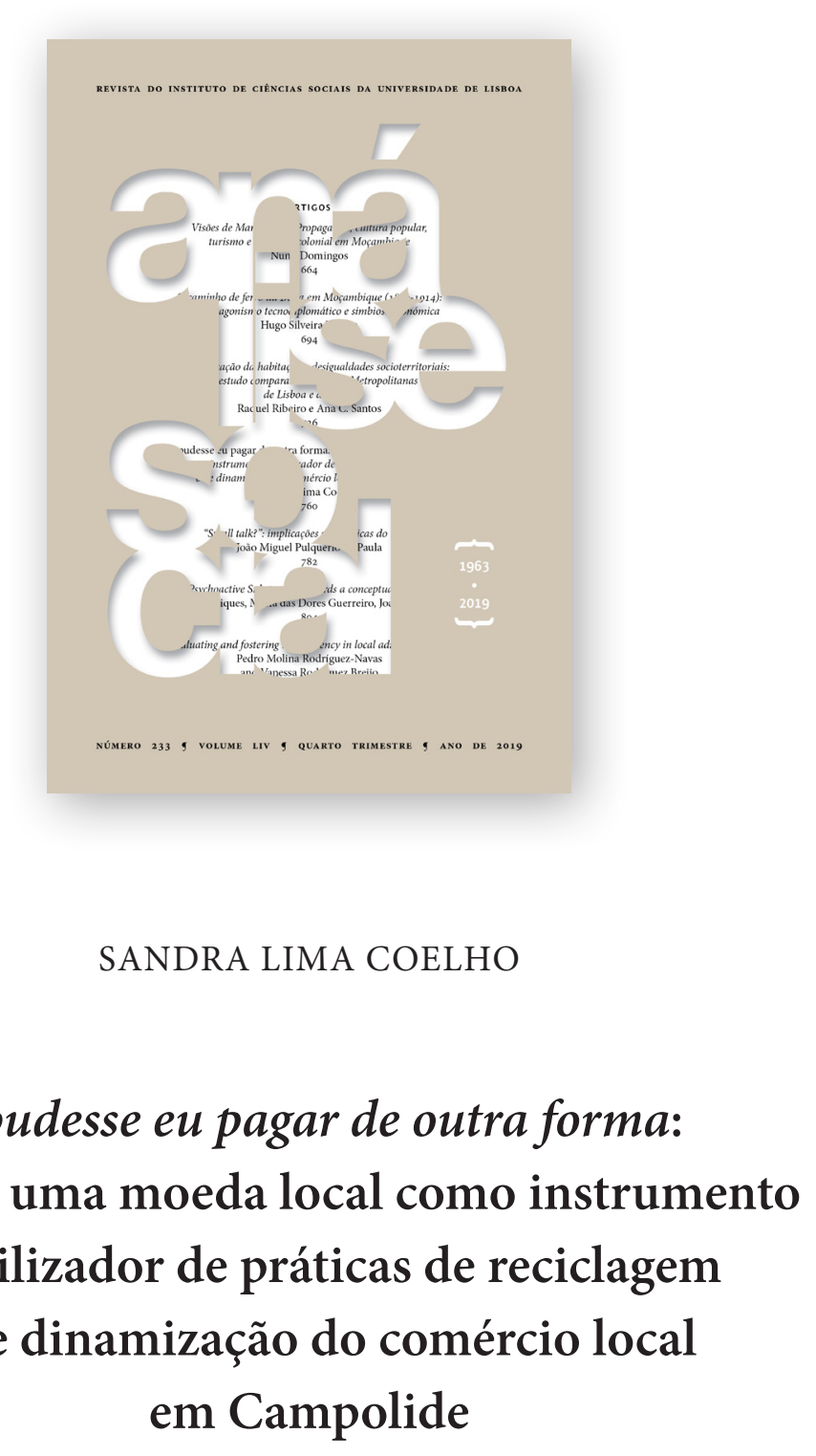

Análise Social, LIV (4. $\left.{ }^{\circ}\right), 2019$ (n. ${ }^{\circ} 233$ ), pp. 760-781 https://doi.org/10.31447/Asoo032573.2019233.04 ISSN ONLINE 2182-2999 
Análise Social, 233, LIV $\left(4 .^{\circ}\right), 2019,760-781$

E pudesse eu pagar de outra forma: o uso de uma moeda local como instrumento mobilizador de práticas de reciclagem e de dinamização do comércio local em Campolide. Neste artigo apresenta-se o modus operandi do "Pago em Lixo", projeto criado pela Junta de Freguesia de Campolide (JFC), em Lisboa, que implementou uma moeda local, o Lixo, com o objetivo de envolver a comunidade na separação de resíduos, e analisam-se as motivações que estão na sua génese. Os dados recolhidos numa entrevista semidiretiva ao presidente da JFC evidenciam que a motivação principal da JFC é de ordem económica: robustecer o comércio e a economia local e reduzir os encargos financeiros no que concerne à limpeza das ruas, mas também fomentar nos moradores a adoção de comportamentos de maior consciência cívica, o que reflete uma moralidade ersatz.

PALAVRAS-CHAVE: moeda local; participação; racionalidade económica; moralidade ersatz.

And could I pay another way: the use of a local currency as a tool to mobilize recycling practices and boost local commerce in Campolide. This article presents the modus operandi of "Pago em Lixo", a project created by the Parish Council of Campolide (PFC), in Lisbon, which implemented a local currency, Lixo, with the aim of involving the community in the separation of waste. One analyzes the motivations that are in its genesis. Data collected in a semi-directive interview with the President of the PFC, shows that the main motivation of the PFC is economic: to strengthen trade and the local economy, and reduce the financial burden on street cleaning, but also encourages residents to perform behaviors of greater civic awareness, which reflects ersatz morality.

KEYWORDS: local currency; participation; economic rationality; ersatz morality.

https://doi.org/10.31447/ASO0032573.2019233.04 


\section{E pudesse eu pagar de outra forma: o uso de uma moeda local como instrumento mobilizador de práticas de reciclagem e de dinamização do comércio local em Campolide}

\section{INTRODUÇÃO}

As moedas locais são moedas alternativas ao dinheiro convencional. Estas moedas são conhecidas pelas suas características de fortalecimento das economias locais e pelo estabelecimento de laços comunitários. Por via do uso de uma moeda local expressam-se laços de solidariedade, estabelecem-se relações de confiança e fortalece-se a identidade da comunidade. Por parte do poder local, quais são as vantagens que se encontram na implementação de uma moeda local? Procura-se promover o exercício de uma cidadania ativa e uma cultura de maior participação social? Serão os fins que subjazem à implementação da moeda local de natureza moral ou meramente económicos? Procuramos obter resposta para estas questões na análise de um caso particular, o da freguesia lisboeta de Campolide, cuja Junta de Freguesia criou uma moeda que circula apenas dentro da sua área geográfica.

Campolide pertence à zona centro da capital portuguesa e conta com cerca de 20 mil habitantes. O "Pago em Lixo" é um projeto no qual se trocam resíduos recicláveis por uma moeda não convencional, o Lixo, que circula em 70 dos 400 estabelecimentos comerciais da freguesia. O projeto foi criado em 2016 e a primeira ação de recolha de resíduos decorreu no final do verão, no dia 17 de setembro do mesmo ano. A Junta de Freguesia de Campolide (JFC) pretende, com este projeto, cumprir dois objetivos: (i) dinamizar o comércio local, fortemente afetado pela crise financeira de 2008 que atingiu de forma particularmente gravosa países como Portugal, Espanha e Grécia, e pela proliferação das grandes superfícies comerciais e (ii) incutir na população hábitos 
de separação de resíduos. A designação da moeda está associada à intervenção e à ação inerentes ao próprio projeto: trocam-se resíduos que possam ser reciclados (papel, plástico, vidro e pilhas) por Lixo, a moeda local criada pela JFC e que só pode ser utilizada no comércio tradicional local.

Esta ação tem por fim envolver a comunidade na separação de resíduos. É uma ação que apresenta um fim moral: consciencializar os cidadãos recenseados naquela freguesia lisboeta para a necessidade da reciclagem dos resíduos e para a limpeza dos espaços públicos, mas é, também, uma ação que visa dinamizar o comércio local. Quais são, então, as potencialidades, os limites e os desafios do "Pago em Lixo"? Como se processa a troca de resíduos por Lixo, a moeda local? Quais são as características deste projeto? Sendo um dos objetivos promover um comportamento cívico de separação e reciclagem de resíduos, que estão na base da proteção ambiental, como é que esse desígnio se cumpre? A JFC promove uma nova moralidade através da mobilização de motivações económicas como veículo para incutir novos comportamentos e hábitos na sua população? Estaremos, efetivamente, perante um processo de construção de uma moralidade artificial, ersatz, como advoga Fevre (2003)? Estas são questões para as quais procuramos obter resposta neste artigo, que resulta de um trabalho de cariz exploratório, no qual procuramos conhecer o modus operandi do "Pago em Lixo", compreender as motivações da JFC para criar este projeto e determinar se essas motivações são, exclusivamente, de natureza moral ou económica, ou se resultam de uma interseção entre ambas. Para cumprir estes objetivos, entrevistámos o presidente da JFC e uma moradora participante no projeto, realizámos pesquisa e análise documental e assistimos a duas ações de recolha de resíduos e respetiva troca desses resíduos por Lixo. Durante os momentos de presença no terreno e de observação mantivemos conversas com informantes privilegiados sobre as motivações para participarem neste projeto.

\section{VALORES MORAIS, VALORES ECONÓMICOS E MOEDAS LOCAIS: \\ CONCEITOS QUE PODEM ENTRECRUZAR-SE, OU REALIDADES INCOMPATÍVEIS?}

Para Smith (1982 [1759]), uma ação moral não pode ser compreendida sem que, antecipadamente, se identifique a natureza da virtude que influenciou essa ação. $\mathrm{O}$ autor sustenta que uma ação não se resume à sua execução, e que há uma reflexão que a antecede. Smith (1982 [1759]) argumenta, igualmente, que o sistema moral se baseia na observação das interações quotidianas. A conduta moral deriva das relações sociais que os indivíduos estabelecem com os restantes membros da sociedade em que vivem. A moral forma-se, 
assim, como uma espécie de ambiente que enlaça os indivíduos, assumindo-se como uma realidade natural que afeta e explica o seu comportamento. Smith (1982 [1759]) faz alusão a um "efeito de espelho": o indivíduo constitui-se como ser humano apenas quando se encontra na presença de outros indivíduos, uma vez que é pela observação das respostas dos nossos interlocutores às nossas ações que tomamos consciência da nossa moralidade.

De outro prisma, Durkheim (1995) afirma que, na sociedade moderna, a moral sustenta-se em laços socias provenientes da divisão do trabalho. A complexidade da sociedade moderna e a diferenciação social que nela persiste exigem novos valores, distintos dos que marcavam as sociedades tradicionais. Estes novos valores deveriam corresponder à diversidade de profissões especializadas que se multiplicam no modelo de sociedade de capitalismo industrial. Assim, Durkheim (1995) defendia a importância das corporações enquanto mecanismos de regulação moral para cada atividade económica. Mas, além da moral profissional, Durkheim (2002) também chamou a atenção para a importância de uma moral cívica na configuração dos valores morais modernos.

Esta moral cívica respeitaria a um conjunto de regras que regulariam a relação entre o indivíduo e o Estado. No entendimento de Durkheim (2002), o Estado é uma instituição à qual pertence a criação e difusão destes novos valores morais. Para o autor, competia ao Estado formular as representações coletivas que deveriam reger a vida social. Neste sentido, podemos afirmar que Durkheim considerava que cabia ao Estado a incumbência de regular a atividade económica, pois esta é uma atividade que faz parte da vida social. Todavia, vivemos numa época em que o mercado é uma instituição social que, por força do processo de disembededdness, enunciado por Polanyi (2012 [1944]) e que corresponde ao desenraizamento da atividade económica do campo social, tende a regular a atividade económica. Assim, verifica-se, na realidade atual, uma alteração àquilo que Durkheim (2002) sugeria, pois não é o Estado que regula a atividade económica, é o mercado.

Permitir que seja o mercado a regular os destinos da sociedade pode, segundo Durkheim (citado por Fevre, 2003, p. 4), acarretar efeitos nefastos para a sociedade. Durkheim (2002) preocupava-se com o fenómeno da prevalência do interesse individual sobre o interesse coletivo, reportando-se ao estado anómico que os indivíduos experimentavam quando a atividade económica assumia primazia sobre os restantes aspetos da sociedade. Esta é, de igual modo, uma preocupação manifestada por Polanyi (2012 [1944]), que se questionava sobre as consequências nocivas que a permissividade perante os avanços do mercado enquanto agente de regulação das atividades sociais poderia acarretar para o destino da própria sociedade. Para Fevre (2003, p. 5), à medida que a racionalidade económica se expande, a moralidade contrai-se, 
recua e a racionalidade económica alastra-se para outras dimensões da vida social, não deixando espaço para a moralidade e esta pouco interfere no comportamento económico, originado um processo de desmoralização da sociedade. Este processo de desmoralização reflete a instrumentalização de valores morais para se atingirem fins que não são morais, mas sim económicos (Fevre, 2003).

Na origem do processo de desmoralização da sociedade está, para Anthony (1977; citado por Fevre, 2003, p. 6), o uso do dinheiro como fonte de todo o valor. Por outras palavras, o uso do dinheiro como medida de valor de todas as coisas estaria na base do processo de enfraquecimento dos valores morais. Durkheim (citado por Fevre, 2003, p. 6) afirma que a moral advém da estrutura social, é fruto da ação dos indivíduos, logo, pode ser alterada. No caso do projeto aqui em análise, esta constatação leva-nos a questionar se a implementação de uma moeda local por parte de uma junta de freguesia pode servir fins morais através da promoção de um comportamento cívico que consiste na ação individual de reciclar resíduos, mas que é, de igual modo, uma ação territorializada e concertada no sentido de fortalecer e dinamizar o comércio e a economia local.

Face ao avanço dos valores económicos e ao recuo dos valores morais, Fevre (2003, pp. 7-8) constata que, na sociedade atual, a moralidade é manufaturada. Nas palavras do autor, "se o capitalismo industrial era sobre desmoralização, a sociedade contemporânea é muito mais sobre a produção de uma moralidade sintética ou instrumental" (Fevre, 2003, p. 8) e é isso que a distingue da sociedade de capitalismo industrial: a capacidade de produzir a própria moralidade. Isto significa que a moralidade pode ser fabricada: a nossa sociedade não produz apenas bens e serviços, produz também a própria moralidade, uma moralidade ersatz (Fevre, 2003). Qual será a relação entre estas novas formas de moralidade sintéticas e instrumentais e o papel que os programas governamentais podem ter na sua construção? Pode o uso do dinheiro e, mais concretamente, de uma moeda local, premiar a ação cívica dos cidadãos de uma localidade e incutir-lhes novos valores morais como a sustentabilidade e proteção ambiental? Atentemos, primeiramente, no papel da moeda na sociedade.

Nem sempre, ao longo da história, se transacionaram bens e serviços através do recurso a uma moeda única. Segundo Tibbett (1997, p. 127), até ao século XIX, a prática vigente consistia no uso de diversas moedas em simultâneo. $\mathrm{Na}$ atualidade, são vários os casos de retorno ao uso de mais do que uma moeda no mesmo território. São as chamadas "moedas comunitárias" (Lietaer e Dunne, 2013; Seyfang e Pearson, 2000), "locais" (Hughes, 2015), "complementares" (Peacock, 2014), "moedas municipais" (Jayaramant e Oak, 
2005) ou ainda "moeda social" (Lucas dos Santos e Silva, 2014) que funcionam, em simultâneo, com a moeda oficial, sem que as substituam.

Como verificámos, as moedas não convencionais assumem uma pluralidade de designações, não existindo, propriamente, uma designação universal e consensual. Neste artigo usamos a designação de moeda local, uma vez que consideramos que, se todas as moedas são dotadas de uma função social, dado que a função económica é uma função social, então todas as moedas são sociais. Assim, defender que só as moedas locais são sociais significa excluir a moeda convencional da sua função social, perspetiva da qual discordamos. Consideramos, igualmente, que a denominação moeda local abrange as dimensões mais expressivas da especificidade destas unidades monetárias: promover o desenvolvimento local através da circulação e não da acumulação, como acontece no sistema dominante, de uma moeda que é localmente produzida, que circula localmente e que preserva a riqueza produzida na própria localidade, o que robustece a economia local.

Numa era caracterizada pela globalização das atividades económicas e do predomínio dos valores económicos como a produção, o sucesso e a realização (Parsons e Smelser, 1956), à medida que a globalização económica se tornou hegemónica surgiram diversos esquemas de moedas locais. Este sistema de moeda foi concebido para fortalecer os laços de comunidades confrontadas com os efeitos da crescente mercantilização da vida (Soares, 2015), mas também para fazer face ao colapso das moedas nacionais (Jayaramant e Oak, 2005, p. 597) e, de igual modo, para procurar soluções ambientalmente mais sustentáveis, respostas para crises económicas e para se construírem comunidades resilientes, nas quais a participação social na vida comunitária possa fortalecer a economia local e a própria comunidade.

As moedas locais detêm características comuns que são enunciadas por diversos autores. Segundo Seyfang e Pearson (2000, p. 58), a implementação destas moedas procura responder aos problemas relacionados com o enfraquecimento das economias locais. Já Lucas dos Santos e Silva (2014) e Peacock (2014) destacam o papel destas moedas face ao enfraquecimento dos laços comunitários, problemas de exclusão social, dificuldades de acesso a bens essenciais e supressão de necessidades básicas. Deste modo, podemos afirmar que as moedas locais contribuem para "reinventar e reestruturar o mercado" (Seyfang e Pearson, 2000, p. 59), pois correspondem a uma forma de economia na qual se valorizam competências e saberes que não são reconhecidos na economia de mercado (Lucas dos Santos e Silva, 2014). É unânime, entre estes autores, que as moedas locais favorecem, igualmente, a autonomia da economia local, assim como o auto-aprovisionamento, ao invés da dependência de bens importados, o que contribui para um desenvolvimento mais 
sustentável e para a construção de economias locais baseadas em justiça social e em relações sociais de interdependência entre os membros da comunidade.

Seyfang e Pearson (2000, pp. 57-58) distinguem três formas de operacionalização destas moedas. A primeira forma é o trânsito de notas que circulam livremente entre indivíduos e estabelecimentos comerciais. Estas notas são utilizadas da mesma forma que a moeda convencional e têm como propósito a revitalização da economia local. A segunda forma consiste num sistema de crédito e de débito entre membros de uma comunidade. As trocas constituem um sistema de crédito mútuo, usado entre indivíduos e que se gera no próprio ato de troca (e.g. LETs, no Reino Unido e no Canadá; sEL, em França). Os LETs são associações locais cujos membros indicam os bens e serviços que procuram e aqueles que podem dar em troca e que emergiram em meados dos anos 1980. A sua expressão aumentou, consideravelmente, na década de 1990. Há um registo central dos créditos e débitos de cada membro. Assim, os indivíduos podem aceder a bens e a serviços em troca da oferta do seu tempo e das suas capacidades para produzir determinados bens ou prestar determinados serviços. O preço destes bens e serviços é calculado em unidades de moeda local virtual. A terceira forma de moeda local considerada por Seyfang e Pearson (2000) é o banco de tempo, que consiste na troca de bens e de serviços usando o tempo como moeda de troca (e.g. Time Dollar, nos Estados Unidos da América). Compete a cada agência de banco de tempo coordenar a oferta e a procura de serviços que os seus utilizadores disponibilizam.

A primeira forma de operacionalização da moeda local enunciada por Seyfang e Pearson (2000), isto é, o trânsito de notas que circulam livremente entre indivíduos e estabelecimentos comerciais é aquela que melhor enquadra o "Pago em Lixo", na medida em que este projeto possibilita que a moeda local, o Lixo, circule entre os moradores de Campolide e os estabelecimentos comerciais dos pequenos comerciantes que aderiram ao projeto, que foi criado com o propósito, precisamente, de revitalizar o comércio local. Consequentemente, a função desta moeda consiste em fortalecer a economia local, uma função que a moeda convencional não cumpre.

Lietaer e Dunne (2013) defendem que a sociedade atual deve repensar a função do dinheiro. Os autores entendem que o dinheiro e o próprio sistema monetário são um problema, mas uma vez que o dinheiro é uma invenção da humanidade, essa realidade é passível de ser modificada e essa mudança passa pela implementação de moedas locais. Não obstante, existem autores que colocam em causa a sustentabilidade destas moedas. É o caso de Evans (2009), que afirma que o uso de moedas locais, de modo sustentável, não é comum. $\mathrm{O}$ autor estudou diversos casos de moedas locais que proliferam pelo globo e concluiu que as pessoas as usam porque delas retiram vantagens económicas 
e que, se esses benefícios não se materializam, acabam por deixar de fazê-lo. As motivações morais não são suficientemente fortes, diz Evans (2009), o que indicia a desmoralização da sociedade e uma presença forte dos valores económicos: se não houver recompensa económica pela ação, esta dilui-se. Evans (2009) nota que existem poucos casos de sucesso de moedas deste cariz. Do seu ponto de vista, os casos bem sucedidos não podem ser entendidos como um compromisso levado a cabo pelas comunidades no sentido de expressarem valores sociais.

Evans (2009) afiança que as moedas locais têm um ciclo de vida curto, o que, na sua ótica, sugere que os objetivos morais que subjazem à utilização destas moedas não são suficientemente fortes para que estas subsistam e resistam à passagem do tempo. Mas será que a utilização de uma moeda local e a sua circulação no interior de uma comunidade podem promover a participação social, o desenvolvimento local e o fortalecimento de laços entre os membros da comunidade? Ornelas (2002) entende que a participação social é um dos elementos fundamentais de uma comunidade. Sem a participação e envolvimento dos cidadãos, a intervenção comunitária carece de sentido. A participação social pode, igualmente, fortalecer o sentimento de pertença à comunidade. Segundo Colombo, Mos e De Piccoli (2001), a participação dos cidadãos na vida da cidade é uma boa forma de melhorar as condições ambientais, melhorar os serviços que a cidade oferece e as condições sociais da comunidade.

Montero (2004) define comunidade como um grupo em constante transformação e evolução e que, nas suas inter-relações, gera um sentimento de pertença e de identidade social e, como explica Guarino, "fazendo com que os seus membros tenham consciência de ser um grupo, fortalecendo a unidade e o potencial social" (Guarino, 2016, p. 239). Chavis e Wandersman (1990) sustentam que a participação pode ser incentivada pelo sentido de pertença a uma comunidade. Esse sentimento pode funcionar como um elemento potenciador do desenvolvimento da comunidade, mas a participação per se, advogam estes autores, não pode proporcionar o desenvolvimento da comunidade.

O sentimento do "nós" é necessário para a construção da identidade local, mas será suficiente para que uma comunidade se desenvolva? Lietaer e Hallsmith (2006) afirmam que as moedas locais providenciam um modo de manter a riqueza que é produzida localmente na própria comunidade, para beneficiar as pessoas que aí vivem, em vez de ser desviada para empresas que, ainda que operando na comunidade, acabam por reencaminhar essa riqueza para as suas respetivas sedes, que se situam fora da comunidade. A moeda local melhora, assim, a economia local e constrói capacidades localmente. Estes autores reportam-se às necessidades não satisfeitas e identificam as 
necessidades comerciais como parte desse leque. No âmbito das necessidades comerciais, os autores nomeiam a ajuda aos negócios locais, no sentido de serem mais competitivos, em função da concorrência que surge por parte do crescimento das grandes cadeias comerciais.

De acordo com as perspetivas associadas à economia formal, é função do mercado adequar a utilização dos recursos disponíveis à satisfação das necessidades. Para cumprir esse desiderato, as moedas locais não são necessárias. E, se a distribuição de dinheiro fosse ótima, não haveria necessidades insatisfeitas. Porém, a realidade é muito diferente. Assim, o ponto de partida para a criação de moedas locais pode ser ir ao encontro de necessidades que as transações com dinheiro convencional não cobrem. Efetivamente, para Lietaer e Hallsmith (2006, p. 9) a criação de uma moeda local pode servir para reforçar a identidade de uma comunidade (reforçar o sentimento de pertença), pode ter um propósito ecológico (o que os autores consideram ser uma razão que se popularizou nos últimos anos) ou premiar um comportamento ecológico que permita contribuir para a sustentabilidade de um determinado sítio. A moeda local pode também, aferem os autores, ser um caminho para um sistema financeiro alternativo, um instrumento capaz de democratizar o acesso a bens dentro de um mercado.

Em Portugal, as iniciativas de moeda local e de mercados solidários são ainda escassas. As primeiras experiências de moeda local em suporte físico datam de 2006 (Lucas dos Santos e Silva, p. 2014). De acordo com as autoras, estas iniciativas destacam-se "pela sua capacidade de criar, mobilizar e fortalecer redes na comunidade" (idem, p. 210). Por outro lado, constatam que "os coletivos de consumidores e as redes de trocas com moedas sociais são bons exemplos de outros modos de consumir e de fazer circular bens e serviços, distanciando-se da racionalidade que caracteriza o consumo capitalista" (idem, p. 211). A moeda local de Campolide representa estas lógicas? Poderá a moeda local de Campolide constituir um estímulo à reflexão dos cidadãos sobre as suas práticas de consumo e conduzir a um consumo mais solidário? Terá esta moeda um "potencial emancipatório que fortaleça outras prerrogativas, tais como a construção de novas sociabilidades, a articulação comunitária para o enfrentamento da vulnerabilidade socioecoómica (...) e a valorização de saberes e fazeres das pessoas" como Lucas dos Santos e Silva (2014, p. 211) advogam ser característico destas moedas? Será a sua utilização uma forma de ação coletiva, territorializada e de intervenção pública, apoiada por financiamento público?

Para descobrirmos mais sobre esta moeda, a sua função e as motivações que desencadearam a sua criação, encetamos um conjunto de procedimentos metodológicos de que damos conta no ponto seguinte. 


\section{MÉTODOS E TÉCNICAS DE INVESTIGAÇÃO}

O nosso olhar analítico incidiu sobre um projeto recente. Deste modo, este é um estudo exploratório, pois ainda não existe muita informação disponível sobre o "Pago em Lixo". Numa fase inicial da pesquisa, procedemos à recolha de informação no site oficial do projeto ${ }^{1}$, consultámos e analisámos o seu regulamento e compilámos diversos artigos publicados na imprensa portuguesa. Depois de examinarmos as informações recolhidas por estes meios tornou-se necessário definir um corpo metodológico que nos permitisse dar resposta às questões que suscitaram a pesquisa. O método mobilizado foi o qualitativo e recorremos à combinação de duas técnicas: entrevista semi-diretiva e observação direta. Adicionalmente, efetuámos registos fotográficos, recolhemos depoimentos em conversas informais mantidas com quatro informantes privilegiados, nomeadamente funcionários da JFC e moradores que participaram nas ações observadas e cujos testemunhos registámos num diário de campo.

Primeiramente, optámos por entrevistar o presidente da JFC, enquanto informante privilegiado no que concerne à origem, desenvolvimento, aplicação e resultados do "Pago em Lixo". Esta entrevista foi realizada presencialmente, e em dois momentos distintos, e permitiu-nos conhecer, de modo mais aprofundado, o modus operandi do projeto, os motivos que estão na sua origem e as representações do presidente da JFC sobre as potencialidades do "Pago em Lixo". Efetuou-se, posteriormente, uma entrevista semi-diretiva, por correio eletrónico, a uma moradora que participou numa das ações observadas, com o intuito de aferir as suas motivações para aderir ao projeto. No âmbito desta pesquisa, recolhemos, igualmente, os depoimentos de quatro outros moradores participantes no projeto. Esses depoimentos foram obtidos em conversas informais mantidas durante os momentos de presença do terreno.

Os objetivos da pesquisa foram facultados aos entrevistados, assim como a garantia de que a informação fornecida seria usada, exclusivamente, para fins académicos e científicos. Embora o discurso do presidente da JFC esteja condicionado por imposições e limitações de pertença a um universo simbólico do qual demonstra dificuldade em afastar-se, nomeadamente no elogio ao sucesso do "Pago em Lixo" (o que nos recordou que o ator social não vive de forma dissociada da rede relacional complexa em que se encontra inserido), o seu relato revelou-se imprescindível para conhecermos, em profundidade, os enredos que desvelam este projeto.

A segunda técnica usada nesta pesquisa foi a observação direta que se materializou na presença no terreno durante duas ações do "Pago em Lixo". 
As ações observadas decorreram no dia 11 de fevereiro de 2017, o primeiro dia em que o projeto voltou a ser posto em prática após uma interrupção para reajustamentos no seu regulamento. As ações decorreram em dois locais distintos da freguesia de Campolide: primeiro, no Alto de Campolide e, depois, no Bairro da Liberdade. Esta presença no terreno permitiu-nos conversar com os participantes, observar a adesão da população ao projeto, compreender como se processa a troca de resíduos por Lixo e observar as características e as interações sociais da população que aderiu àquela ação durante esse procedimento.

\section{ANÁlise E DISCUSSÃO DE RESULTADOS}

O "Pago em Lixo" foi apresentado no dia 15 de setembro de 2016 e a primeira ação de recolha de resíduos e consequente troca pela moeda Lixo decorreu dois dias depois. Como funciona, na prática, este projeto? A JFC monta bancas para a recolha e pesagem de resíduos recicláveis em zonas específicas da freguesia, sendo que as ações são mensais e, no mesmo dia, decorrem duas ações em locais distintos. Os resíduos entregues são pesados numa balança destinada a esse efeito. O Lixo tem um lastro em euros: por cada Lixo que circula há um euro que lhe corresponde no "Banco Central de Campolide", como o designa o presidente da JFC. Cada Lixo corresponde a $1 €$ e a quantidade de euros correspondente a cada quilo de resíduos varia em função do tipo de resíduos entregue, conforme se pode verificar no quadro 1.

QUADRO 1

Tabela de conversão dos resíduos em Lixo.

\begin{tabular}{cc}
\hline Quantidade de lixo & Valor correspondente em Lixo \\
\hline 3 quilos de vidro & 1 Lixo $(1 €)$ \\
1 quilo de papel ou cartão & 1 Lixo $(1 €)$ \\
1 quilo de plástico ou embalagens & 1 Lixo $(1 €)$ \\
1 quilo de pilhas & 1 Lixo $(1 €)$ \\
\hline
\end{tabular}

Cada cidadão recenseado em Campolide só pode trocar, no máximo, 10 quilos de resíduos por dia. A troca de resíduos por Lixos é limitada aos recenseados na freguesia de Campolide por questões relacionadas com a viabilidade económica do projeto, uma vez que o financiamento é parco: de acordo com os dados recolhidos junto da JFC, o plafond máximo para o projeto é de $€ 15500$ por ano e de $€ 1$ ooo por cada ação. A moeda Lixo só pode ser utilizada nas lojas de comércio tradicional aderentes. Estas lojas estão identificadas com 
o dístico da iniciativa. Convertem-se, assim, resíduos urbanos recicláveis em moeda de troca para se fazer compras, exclusivamente, nas lojas de comércio tradicional locais. Os comerciantes aderentes são, posteriormente, ressarcidos pela entidade do valor das compras efetuadas com a moeda local, trocando os Lixos por euros no "Banco Central de Campolide", ou podem trocar os Lixos entre si, fazendo compras noutros estabelecimentos comerciais que aceitem esta moeda.

Nas ações de troca de resíduos por Lixo observadas apurámos que as pessoas chegam aos pontos de recolha munidas de sacos com resíduos para trocar, desde vidro e plástico a papel. Nos momentos observados, verificámos que uma trabalhadora da JFC pede o cartão de cidadão ou o número de eleitor aos moradores, de forma a poder comprovar através de uma base de dados acessível a partir de um computador portátil, que esse morador é recenseado na JFC. Assim, a JFC garante que não há fraude e que apenas os recenseados em Campolide podem participar, tal como consta no regulamento. Numa fase inicial do projeto registaram-se casos de fraude que levaram à sua suspensão:

Havia algumas pessoas que acordavam naquele sábado de manhã e "ei, está ali a Junta e se nós levarmos vidro e papel eles dão-nos dinheiro para se consumir ali no café do André! Ei pá, mas eu não tenho aqui em casa! E agora onde é que a gente vai arranjar isso?” Então, iam ao Ecoponto e rebentavam o Ecoponto todo. Em especial, a parte do vidro e a parte do papel. Isto aconteceu duas vezes. Além de ser uma fraude ao projeto, porque a ideia não é ir ao Ecoponto buscar o lixo, é fazer a separação em casa e depois porque tinha um prejuízo associado, porque lá está, a Junta de Freguesia depois tinha de mandar arranjar aquilo. E a reparação de Ecopontos é uma coisa que não é assim tão barata quanto isso. (...) E como nós não podemos controlar, presencialmente, todos os Ecopontos da freguesia, aquilo que nós decidimos é que a partir do momento em que haja, durante uma ação do "Pago em Lixo", um Ecoponto vandalizado, toda a gente sabe que a ação termina imediatamente. Desta forma, vai-se permitir que sejam os próprios vizinhos a desincentivar os outros de o fazer ou, de alguma forma, de se controlarem entre si. [presidente da JFC, 34 anos, licenciado]

Neste excerto está patente a preocupação do presidente da JFC com os custos associados à recuperação dos Ecopontos danificados, mas também o propósito de base do projeto: sensibilizar os moradores para a separação de resíduos. É também percetível a sua intenção de envolver a população no projeto, atribuindo-lhe, ainda que simbolicamente, um papel de vigilância e de monitorização do comportamento dos moradores no que concerne à sua participação nas ações de recolha de resíduos.

Atentámos, no primeiro local de recolha, que os indivíduos que traziam resíduos para trocar por Lixos apresentavam características heterogéneas: entre 
os cerca de 20 indivíduos que se deslocaram ao Alto de Campolide naquela manhã, vislumbrámos idosos sós, adultos acompanhados de crianças (invariavelmente eram as crianças que recebiam os Lixos das mãos dos trabalhadores da JFC) e grupos de jovens que se deslocavam juntos ao local. No Bairro da Liberdade a adesão foi muito menos expressiva. Na totalidade, deslocaram-se ao local cinco adultos, dois deles acompanhados por crianças que se mostraram entusiasmadas por receberem os Lixos das mãos dos trabalhadores da JFC ali presentes. As crianças reagiram àquilo a que Lietaer, Hallsmith (2006, p. 9) entendem como "premiar um comportamento ecológico" e que, neste caso, contribui para a sustentabilidade ecológica da freguesia de Campolide e da cidade de Lisboa. A questão que colocamos é se esta "pedagogia pelo exemplo" não poderá acarretar eventuais efeitos perversos, a longo prazo, na formação da consciência cívica destas crianças, na medida em que se lhes está a ser ensinado que um comportamento que deveria ser desempenhado em função de um valor moral, o de promover a proteção ambiental, é, afinal, concretizado em função de uma recompensa financeira.

$\mathrm{Na}$ comunidade de moradores recenseados em Campolide criou-se uma rede local que se encontra graficamente representada na figura 1. Nessa rede, o papel da JFC dilui-se em diversos eixos de atuação: emissão da moeda Lixo, controlo de emissão dessa moeda, recolha de resíduos, troca de resíduos por Lixos. A moeda Lixo circula dentro de uma comunidade que, neste caso, é a freguesia de Campolide. Para terem acesso à moeda, basta que os recenseados em Campolide entreguem resíduos recicláveis nos dias e pontos de recolha indicados pela JFC.

Com esta rede a economia local sai fortalecida, assim como os processos de dinâmica social de proximidade. Por outro lado, de acordo com o seu presidente, a JFC sai beneficiada no que concerne à poupança de custos, tanto na redução FIGURA 1

Estrutura da rede local da moeda Lixo

de trabalhadores afetos à varredura e limpeza das ruas, como no combustível que é gasto nesse processo:

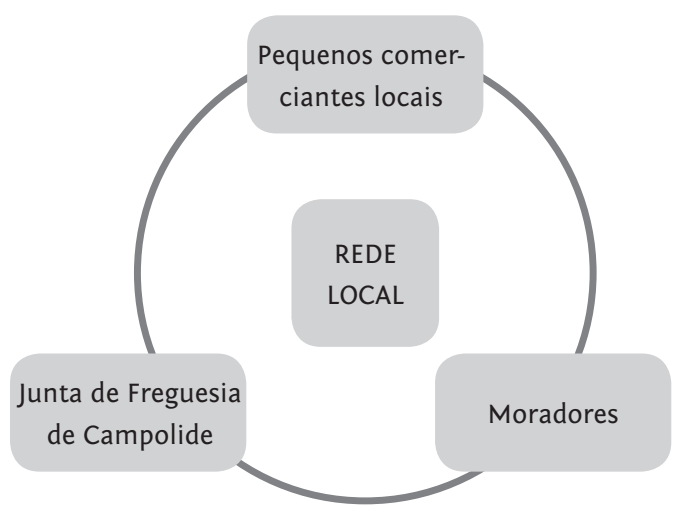


[...] Até porque depois isso pode, nos próximos anos, gerar uma poupança. (...) A médio e a longo prazo nós vamos recolhendo benefícios do facto de as pessoas melhorarem os seus índices de civismo no que respeita à higiene urbana e separação de resíduos, por que isso tem toda uma pegada económico-financeira associada e que, se as pessoas tiverem comportamentos cívicos mais elevados... Se em vez de podermos ter 25 varredores, pudermos ter 15 e investir os outros 10 trabalhadores noutras áreas como, por exemplo, apoio social direto, é muito melhor. (...) Pode poupar-se no número de trabalhadores e nos meios associados [à limpeza das ruas], como o combustível que se gasta. (...)Tudo isso gera economia. [presidente da JFC, 34 anos, licenciado]

Para se reportar ao impacto do "Pago em Lixo" o presidente da JFC apoia-se em dimensões como a superação da capacidade da JFC para dar resposta à quantidade de resíduos recolhida nas ações do projeto, sendo que chegou a haver ações em que o plafond de $1000 €$ estipulado para cada ação se esgotou. Por outro lado, coloca-se a questão do sucesso mediático do "Pago em Lixo" que atraiu não só a imprensa nacional como internacional. Este sucesso mediático ajudou, inclusivamente, a que alguns dos comerciantes mais resistentes a aderir ao projeto acabassem por fazê-lo. O presidente da JFC revela que, numa fase inicial, a JFC efetuou um levantamento de todos os estabelecimentos comerciais da freguesia. Depois, os pequenos comerciantes foram convidados, por carta, para aderirem ao projeto. Nesse contacto foi divulgado junto dos comerciantes o protocolo do "Pago em Lixo", que é uma espécie de contrato que regula a parceria entre o comerciante e a JFC. Este procedimento não foi bem sucedido, pois a JFC recebeu uma quantidade reduzida de respostas. Assim, acionou um outro meio de mobilização que consistiu numa ação de sensibilização nas instalações da JFC à qual compareceram apenas cinco comerciantes. Todavia, assim que o projeto começou a ser divulgado na comunicação social, a situação inverteu-se e foram os próprios comerciantes a procurar a JFC para aderirem ao projeto.

Atualmente, dos 400 estabelecimentos comerciais de Campolide, 70 aderiram ao "Pago em Lixo" e são, maioritariamente, cafés, pastelarias, restaurantes, mercearias, cabeleireiros, peixarias e talhos. O número de comerciantes aderentes é pouco significativo, mas o presidente da JFC entende que, se atendermos às características do comércio tradicional da freguesia, é um bom número:

[...] Em Campolide temos um comércio muito antigo e os antigos têm sempre mais tendência a resistir a estes novos projetos. Os estabelecimentos comerciais de Campolide são, na sua maioria, estabelecimentos comerciais muito antigos. E as pessoas são mais antigas, menos permeáveis a este tipo de iniciativas e mais desconfiadas. (...) As pessoas viam 
um contrato... porque tinha de haver uma formalização por trás, não é? Tem de haver um contrato entre a Junta de Freguesia e os comerciantes para definir as regras e o relacionamento. E muita gente, muitos comerciantes, sobretudo aqueles mais velhos, assustados com a crise, perante um contrato que envolve dinheiros, acharam que, de uma forma ou doutra, aquilo poderia ter despesas, pronto...Houve alguma resistência. [presidente da JFC, 34 anos, licenciado]

Questionámos a JFC sobre a quantidade de resíduos recolhida nas ações do "Pago em Lixo", o que nos permitiu aferir que, desde a primeira ação do projeto, encetada a 17 de setembro de 2016 e até fevereiro de 2018, os moradores de Campolide trocaram 2003 quilos de vidro, 963 quilos de plástico/ embalagens e 1073 quilos de papel/cartão por Lixos. Estes números respeitam somente aos resíduos recolhidos durante o período de tempo em que o projeto está a vigorar e a JFC não dispõe de informação prévia que nos permita efetuar comparações e, assim, perceber se se registou, ou não, um aumento do número de resíduos reciclados. Deste modo, o sucesso que o presidente da JFC associa ao "Pago em Lixo" passa mais pela exposição mediática do projeto e pelo esgotamento do plafond para alguns dias da ação de recolha de resíduos do que, propriamente, pelos resultados obtidos, uma vez que não é possível, ainda, medir esses resultados:

Só a CML é que vê a quantidade de resíduos que recolhe em Campolide, e só a CML poderia determinar se, de facto, as pessoas de Campolide estão a reciclar mais agora do que antes da implementação do "Pago em Lixo" e a recorrer mais aos Ecopontos. [presidente da JFC, 34 anos, licenciado]

Uma outra forma que o presidente da JFC encontra para sublinhar o impacto positivo do "Pago em Lixo" é, por um lado, a de nenhum dos comerciantes aderentes ter desistido do projeto e, por outro lado, os comerciantes fazerem circular a moeda entre si, ao invés de se deslocarem à JFC para trocarem os Lixos por euros:

[...] quando há uma quantidade tal de moeda a circular que já permite uma economia que funciona por si, independentemente do "Banco Central de Campolide", digamos assim, é sinal de que o projeto ganhou alguma escala, independentemente de nós, no máximo, termos $7500 €$ a circular. Por si só, já garantiu isso. Portanto, junto dos comerciantes, aquilo que eu acho que mediu o sucesso foi isto... Foi o facto de, depois de o projeto ter sido lançado, ter aparecido mais gente a querer aderir e não o fenómeno contrário. [presidente da JFC, 34 anos, licenciado] 
O facto de o Lixo continuar a circular entre os comerciantes, ao invés de ser trocado por euros, aproxima-se daquilo que Lucas dos Santos e Silva (2014, p. 211) caracterizam como distante "da racionalidade económica que caracteriza o consumo capitalista". Com efeito, esta troca de Lixos entre os comerciantes reflete o espírito de fortalecimento de laços entre os membros da comunidade, que é intrínseco à utilização das moedas locais e é espelho de um consumo solidário entre os comerciantes. A circulação de Lixos pela comunidade permite, igualmente, aferir que a utilização desta moeda contribui para que a economia local funcione de forma independente, para que haja uma certa autonomia na comunidade, o que vai ao encontro do que é sustentado por Seyfang e Pearson (2000), Peacock (2014) e Lucas dos Santos e Silva (2014) no que concerne ao contributo das moedas locais enquanto elemento de estabelecimento de relações sociais de interdependência entre os membros de uma comunidade e de auto-suficiência da economia local.

Os dados obtidos na entrevista realizada ao presidente da JFC permitem-nos concluir que o "Pago em Lixo" surgiu pela necessidade de resolver dois problemas detetados na freguesia de Campolide: a crise do comércio tradicional e a parca higiene urbana. Segundo o relato deste entrevistado existem, em Campolide, zonas tão afetadas pela ausência de hábitos de higiene urbana em espaço público que, quando a varredura das ruas passou a ser da competência da JFC, tornou-se urgente combater aquele problema. Numa equipa executiva composta por 10 pessoas com idades compreendidas entre os 25 e os 35 anos, com áreas de formação tão diversificadas quanto as do Direito, Marketing, Design e Serviço Social, a inspiração para a criação de uma moeda local partiu do modelo do Banco de Palmas, no Brasil, e surgiu como modelo para a dinamização do comércio local. Depois, segundo o presidente da JFC "colocou-se a questão de a que é que poderia associar-se uma moeda local na freguesia". E, tendo em conta os problemas de lixo aí existentes, a ideia de associar a moeda à separação de resíduos afigurou-se como uma medida possível para minorar este problema.

Apesar de já ter levado a cabo outros projetos de dinamização do comércio local, o presidente da JFC considera que "falar com os comerciantes e tentar fazer formações e um apelo à modernização (...) é complicado. Se eles já estavam estrangulados, se já estão sufocados, onde é que eles têm dinheiro para investir? Não têm! Ainda para mais, em alturas de contração de crédito." Assim, a criação de uma moeda local despontou como uma medida que poderia abranger um número mais alargado de comerciantes, o que atesta a teoria de Lietaer e Hallsmith (2006), que enunciam que um dos fitos da criação de uma moeda local pode ser, precisamente, o de proporcionar ajuda aos negócios locais, depauperados pela proliferação de grandes cadeias comerciais e 
pelas crises financeiras. Em simultâneo, a JFC criou uma campanha de incentivo para que os moradores separem e reciclem os resíduos, uma vez que, de acordo com o presidente da JFC, as campanhas habituais não surtiram o efeito desejado: "as pessoas acham que as campanhas são muito giras, mas não as respeitam (...) quem já fazia a [separação de resíduos] vai continuar a fazer e não é por aí que cativamos novas pessoas". Deste modo, associou-se um benefício económico ao comportamento das pessoas com o intuito de que esse benefício resultasse a favor do fortalecimento do comércio local e da sustentabilidade ambiental da freguesia.

Segundo Fevre (2003, p. 2), o comportamento económico tem sido definido e estudado sem nenhuma referência às motivações e significados que as pessoas atribuem à ação económica. $\mathrm{O}$ autor sustenta que o indivíduo até pode, de facto, ser motivado pelo desejo de maximizar benefícios e minimizar custos, acumular recursos e adquirir bens ao menor custo possível. Todavia, Fevre (2003, p. 2) defende que é necessário verificar se estas assunções teóricas têm um correlato na prática, e afirma que não é porque o comportamento decorre em contexto económico que o seu significado é, exclusivamente, de cariz económico. Para este autor, o comportamento económico nem sempre é economicamente motivado e não tem apenas significado económico. As representações do presidente da JFC sugerem que a motivação económica associada à adoção de um determinado comportamento cívico poderia resultar melhor do que uma campanha de sensibilização que procurasse levar as pessoas a separar e a reciclar os resíduos e a consumir nos estabelecimentos de comércio tradicional:

[...] pensamos que o benefício económico direto, portanto, o premiar financeiramente uma determinada atitude, uma determinada conduta, podia ser a melhor forma de levarmos as pessoas a adotarem esse comportamento, ou a continuarem nesse comportamento. [presidente da JFC, 34 anos, licenciado]

As motivações dos agentes sociais para levarem a cabo um determinado comportamento não são perenes. Pelo contrário, alteram-se e são situacionais. Como enunciámos previamente, Evans (2009) sustenta que as motivações morais não são suficientemente fortes para que as pessoas adiram às moedas locais. Este autor declara que as moedas locais têm um ciclo de vida curto e daí infere que, provavelmente, os objetivos morais que subjazem à sua utilização não são suficientemente fortes para que estas moedas subsistam e resistam à passagem do tempo. Esta teoria de Evans (2009) parece encontrar eco nas representações que o presidente da JFC tem acerca do futuro do "Pago em Lixo". Do ponto de vista deste entrevistado, assim que o incentivo económico 
que mobiliza os moradores de Campolide a aderir ao projeto e a utilizar a moeda local cesse, o próprio projeto extinguir-se-á. Analisando as suas palavras à luz da teoria weberiana, concluímos que a ação de troca de resíduos por Lixo corresponde a uma ação instrumental, motivada por fins económicos, que corresponde ao tipo-ideal de ação racional instrumental weberiana. No discurso do presidente da JFC está patente que os recenseados na JFC aderem ao "Pago em Lixo" em função da recompensa económica que daí advém:

[...] vamos chegar a um ponto em que o projeto já captou toda a gente que tinha a captar. E aqueles que não captou é porque são impermeáveis até a este estímulo. E que, portanto, não adotarão este novo comportamento. Ou deixarão de adotar, quando não houver compensação financeira. (...) Tanto podemos acabar este ano como podemos continuar. Eu acho que ele depois se tornará redundante dentro de uma comunidade de 15/20 mil pessoas. Já não tem efeitos práticos de ampliação deste comportamento. [presidente da JFC, 34 anos, licenciado]

Por outro lado, os testemunhos dos participantes no projeto não corroboram as representações do presidente da JFC sobre as motivações dos residentes, e sugerem que a participação no "Pago em Lixo" não é um comportamento totalmente instrumental. Há valores morais que se juntam à motivação económica:

[Participo] pela preservação do meio ambiente e incentivo ao comércio local da minha freguesia. Sempre que possível, levo o meu filho de 6 anos. É uma belíssima iniciativa de incentivo à reciclagem, que ele adora fazer. E ainda recebe uma recompensa! Há muitos anos que faço a separação e reciclagem do lixo em casa. (...) Tento manter boas práticas (poupança de água, eletricidade). [Se o "Pago em Lixo" fosse suspenso, eu continuaria a reciclar o lixo, com toda a certeza! [coordenadora de Gabinete de Comunicação, 43 anos, licenciada]

Eu adiro ao "Pago em Lixo" não por precisar do dinheiro, mas por querer ajudar a preservar o planeta. Mas não tenho qualquer problema em admitir que se isto me ajuda a pagar os medicamentos da minha avó na farmácia, então, ainda melhor! Se isto permite que eu contribua para o meio ambiente e, ao mesmo tempo, pague os medicamentos da minha avó, então eu vou fazer isto!" [Estudante do $3 .^{\circ}$ ano da licenciatura em psicologia, 21 anos].

Weber (1994 [1922]) sustenta que a ação social é orientada por fins e por valores que refletem a visão do mundo intrínseca a cada agente e a cada grupo social. Para o autor, os valores, os meios e os fins explicam o sentido da ação. A ação racional-instrumental envolve um propósito claro e o indivíduo mobiliza os meios mais eficientes para atingir esse fim. Se atentarmos às palavras 
de Weber (1979), a ação política que envolve tomada de decisão aproxima-se deste tipo-ideal de ação. No caso em análise, reciclar resíduos é um meio para minimizar os custos da JFC com a limpeza dos espaços públicos. Por seu turno, a ação da JFC, ao criar o projeto "Pago em Lixo", pode enquadrar-se no ideal-tipo da ação racional-instrumental, na medida em que se calculou uma combinação particular de medidas políticas que vão minimizar os custos da JFC, tanto a nível económico como ambiental. Por outro lado, os relatos dos participantes do projeto sugerem que a sua adesão ao "Pago em Lixo" é uma ação racional em relação a um valor (a proteção ambiental) e não apenas uma ação economicamente orientada. As ações de reciclagem destas participantes, ainda que não estejam unicamente associadas ao interesse económico, relacionam-se com esse interesse. Mas, conjuntamente, envolvem os seus valores, as suas representações e as suas crenças e estas dimensões influenciam o seu comportamento. São, nesta medida, ações que se encaixam no ideal-tipo weberiano de ação racional-valorativa.

\section{NOTAS CONCLUSIVAS E PISTAS DE REFLEXÃO PARA FUTURAS INVESTIGAÇÕES}

Numa economia de proximidade, os recursos da comunidade não se dispersam, são aplicados localmente e isso verifica-se no caso do projeto "Pago em Lixo": os resíduos convertem-se na moeda Lixo que, por sua vez, se troca por bens e serviços no comércio tradicional local. Os comerciantes da freguesia são ressarcidos pela JFC, ou optam por fazer circular a moeda entre si, em vez de trocarem os Lixos por euros. Antes de findar o processo, que culmina na troca de Lixos por euros, a moeda já circulou por vários membros da comunidade. $\mathrm{O}$ "Pago em Lixo" é um projeto que constitui um investimento da JFC no comércio local e, simultaneamente, uma recompensa aos moradores recenseados em Campolide por levarem a cabo um comportamento cívico relacionado com a reciclagem. Procura-se, assim, fomentar uma cultura de maior participação na vida da comunidade através de um incentivo económico. O benefício económico atribuído aos moradores tem como fito o fortalecimento do comércio e da sustentabilidade ambiental na freguesia. Seria interessante, numa investigação futura, recolher dados juntos dos comerciantes com o intuito de perceber se esse incentivo económico teve, ou não, impacto na manutenção dos seus estabelecimentos e, nessa medida, podermos aferir qual o sucesso da iniciativa junto dos comerciantes.

O impacto da introdução da moeda local em Campolide apenas poderá ser avaliado a longo prazo. Não foi possível saber, através da JFC, se aumentou, ou não, o número de resíduos recicláveis desde a implementação do "Pago em 
Lixo". Não é possível antever se os moradores de Campolide irão, ou não, continuar a separar resíduos quando o projeto se extinguir. Será que este comportamento se mantém apenas enquanto o incentivo económico existir, ou, por outro lado, os comportamentos de reciclagem, incentivados por fins económicos, poderão, efetivamente, enraizar-se na comunidade e sobreviver ao fim do financiamento da medida? Os depoimentos dos participantes que auscultámos indiciam que a ação de reciclagem perdurará, mas o reduzido número de depoimentos recolhidos não nos permite compreender se esta intenção é uma tendência entre os moradores. Seria importante, em investigações futuras, aumentar o número de entrevistas, de modo a compreender se se trata, efetivamente, de uma intenção generalizada na comunidade.

Tornar-se-á a reciclagem e depósito de resíduos nos respetivos contentores uma ação menos instrumental e mais rotineira, ou tradicional, produto de aprendizagem e da experiência, como diria Weber (1979)? Weber (1979) poderia afirmar, igualmente, que a separação de resíduos pode corresponder a uma ação racional orientada por valores, isto é, uma ação determinada pela crença no valor inerente de determinado comportamento, independentemente do seu resultado. Tal significa que a ação de separação de resíduos pode decorrer pelo próprio significado da ação e não pela compensação financeira que dela se retira. Eventualmente, o desenvolvimento de ações de sensibilização associadas ao "Pago em Lixo" para as questões da reciclagem junto da população da freguesia, nomeadamente entre os adolescentes, poderá consolidar estas práticas ecofriendly. Refira-se que a JFC promove o "Pago em Lixo" nas escolas da freguesia, de modo a sensibilizar as crianças para a importância da aquisição de hábitos de reciclagem, o que também poderá contribuir, a longo prazo, para o prolongamento destas práticas.

Os dados recolhidos permitem concluir que a iniciativa de moeda local criada pela junta de freguesia incita os moradores de Campolide a participarem de forma ativa na vida da comunidade, a serem solidários com os pequenos comerciantes e a contribuírem, com o uso da moeda local, para o fortalecimento da economia local. A utilização desta moeda contribui para a sustentabilidade ambiental e comercial da freguesia e, igualmente, para o aumento do poder de compra dos recenseados em Campolide, ainda que de forma marginal, atendendo ao limite imposto de troca de 10 quilos de resíduos por Lixo por cada dia de ação.

Como referem Seyfang e Pearson (2008), a implementação de moedas locais procura dar resposta a problemas relacionados com o enfraquecimento das economias locais, e o "Pago em Lixo" surge como uma tentativa de revitalização económica de Campolide. Por outro lado, à semelhança do que referem Colombo, Mos e De Piccoli (2001), a participação cívica na vida de uma 
comunidade contribui para o sentimento de pertença a essa comunidade. Mas, sendo este um estudo exploratório no qual se entrevistaram somente duas pessoas e se mantiveram conversas informais com quatro dos participantes in loco, não dispomos de dados que nos permitam afirmar que esse sentimento de pertença exista. Essa será uma pista de reflexão para uma investigação futura.

Este estudo exploratório permitiu-nos perceber o funcionamento da rede que se formou entre a JFC, os residentes e os comerciantes no âmbito do "Pago em Lixo", e identificar os motivos da JFC para criar o projeto e esta moeda local. Concluímos que a revitalização do comércio tradicional e a redução de custos, a longo prazo, com a limpeza dos espaços públicos, foram os principais objetivos, apesar de o fomento de comportamentos de maior consciência cívica nos moradores da freguesia no que concerne à higiene urbana e à sustentabilidade ambiental, estejam também implícitos nos propósitos da iniciativa.

No que concerne à importância dos valores na sociedade portuguesa, Pais (1998) sustenta que os princípios materialistas como a segurança financeira, social e familiar, continuam a ser a tendência dominante no nosso país, apesar de assistirmos também ao despontar de valores pós-materialistas como a solidariedade ou a ecologia. Seguindo este raciocínio, podemos concluir que as motivações da JFC para criar o projeto "Pago em Lixo" espelham a interseção destas duas tendências porquanto obedecem a uma lógica de racionalidade económica e, nessa medida, seguem valores materialistas, mas contribuindo para promover valores pós-materialistas como a sustentabilidade e a defesa do ambiente.

\section{REFERÊNCIAS BIBLIOGRÁFICAS}

Chavis, D. M. e WANDERsman, A. (1990), "Sense of community in the urban environment: a catalyst for participation and community development". American Journal of Community Psychology, 18(1), pp. 55-81.

COLOMbo, M., MOs, C. e DE PICCOLI, N. (2001), "Sense of community and participation in urban contexts". Journal of Community \& Applied Social Psychology, 11(6), pp. 457-464.

Durkheim, É. (1995), A Divisão do Trabalho Social, São Paulo, Martins Fontes.

Durkheim, É. (2002), Lições de Sociologia, São Paulo, Martins Fontes.

Evans, M.S. (2009), "Zelizer's theory of money and the case of local currencies". Environment and Planning, 49, pp. 1026-1041.

Fevre, R. (2003), The New Sociology of Economic Behaviour, Londres, Sage Publications.

GUARINo, A. (2016), "O movimento das cidades em transição e os processos psicossociais". In H. Veloso Neto e S.L. Coelho (eds.), Movimentos Sociais e Participação Cívica, Civeri Publishing.

HUGHES, N. (2015), “The community currency scene in Spain”. International Journal of Community Currency Research, 19(Winter), pp. 1-11. 
JAYARAMAN, R., OAK, M. (2005), “The signalling role of municipal currencies in local development”. Economica, New Series, 72 (288), pp. 597-613.

lietaer, B., hallsmith, G. (2006), "Community currency guide" Global Community Initiatives. Available from: http://www.globalcommunity.org/gc/newsfiles/25/Community\%20 Currency\%20Guide.pdf [Consultado a 23-02-2017].

Lietaer, B., Dunne, J. (2013), Rethinking Money. How New Currencies Turn Scarcity Into Prosperity, São Francisco, Berrett-Koehler Publishers Inc.

LuCAS dos santos, L.L., Silva, B.C. (2014), "Mercados de trocas e moedas sociais em Portugal continental: os desafios de uma cultura de emancipação social”. Otra Economia Revista Latinoamericana de Economia Social e Solidária, 8(15), pp. 210-219.

montero, M., (2004), Introducción a la Psicología Comunitaria, Buenos Aires, Paidós.

ORNELAS, J. (2002), "Participação, empowerment e liderança comunitária". Comunicação apresentada na III Conferência Desenvolvimento Comunitário e Saúde Mental (pp. 5-13), Lisboa, Instituto de Psicologia Aplicada.

PAIs, J. M. (coord.) (1998), Gerações e Valores na Sociedade Portuguesa Contemporânea, Lisboa, Instituto de Ciências Sociais da Universidade de Lisboa, Secretaria de Estado da Juventude.

PARsons, T., SMELSER, N. J. (1956), Economy and Society: a Study in the Integration of Economic and Social Theory, Londres, Routledge.

PEACOCK, M. S. (2014), "Complementary currencies: history, theory, prospects". Local Economy, 29(6-7), pp. 708-722.

POLANYI, K. (2012 [1944]), A Grande Transformação, Lisboa, Edições 70.

SEYFANG, G., PEARSON, R. (2000), “Time for change: international experience in community currencies". Development, 43(4), pp. 56-6o.

smith, A. (1982 [1759]), The Theory of Moral Sentiments, The Glasgow Edition of the Works and Correspondence of Adam Smith, $7^{\text {th }}$ ed., Indianapolis, Liberty Fund.

SOARES, C. (2015), "O trabalho na ontologia da vida: implicações éticas". Journal of Studies on Citizenship and Sustainability, 1, pp. 32-46.

тівветт, R. (1997), “Alternative currencies: a challenge to globalization?". New Political Economy, 2(1), pp. 127-135.

WEber, M. (1994 [1922]), Economia e Sociedade: Fundamentos da Sociologia Compreensiva, São Paulo, Editora Universidade de Brasília.

weber, M. (1979), Ensaios de Sociologia, Rio de Janeiro, Zahar Editores.

Recebido a 01-08-2017. Aceite para publicação a 16-05-2019.

COELHO, S.L. (2019), "E pudesse eu pagar de outra forma": o uso de uma moeda local como instrumento mobilizador de práticas de reciclagem e de dinamização do comércio local em Campolide". Análise Social, 233, LIV $\left(4 .^{\circ}\right)$, pp. $760-781$.

Sandra Lima Coelho » scoelho@porto.ucp.pt » IS-UP, Instituto de Sociologia da Faculdade de Letras da Universidade do Porto e Católica Porto Business School Universidade Católica Portuguesa » Rua Diogo Botelho, 1327 - 4169-005 Porto, Portugal » https://orcid.org/oooo-0003-4155-9532. 